\title{
Herbicide applications for replacing toxic tall fescue with AR542 tall fescue - can summer smother crops be eliminated?
}

\author{
J.G. ANDRAE ${ }^{1}$ and N.S. HILL ${ }^{2}$ \\ ${ }^{1}$ Clemson University, Clemson SC USA \\ ${ }^{2}$ University of Georgia, Athens GA USA \\ jandrae@clemson.edu
}

Recent commercial development of tall fescue containing a nontoxic endophyte has renewed producer interest in replacing stands of toxic tall fescue. The currently recommended spray-smotherspray (S-S-S) replacement method is lengthy, costly, and requires successful establishment of warm-season annual forages. Poor producer acceptance of this replacement method is limiting the adoption of novel endophyte technology in the United States. Sequential fall glyphosate applications can effectively remove established toxic tall fescue; however, increasing the time period between split fall applications could improve the efficacy of this method. The objective of this study was to examine various fall glyphosate application intervals versus the standard S-S-S technique for replacing toxic tall fescue with tall fescue infected with AR542. Plots of toxic tall fescue near Blairsville and Athens Georgia were mowed during spring to prevent seed production. Six $1.5 \times 6.1 \mathrm{~m}$ replicate plots at each location were randomly allotted to the following treatments: control (no herbicide); SS-S (pearl millet summer smother crop); single fall glyphosate application applied at fall planting; or double fall glyphosate applied at either 2,4 , or 6 week intervals prior to planting. All treatments, including single application and S-S-S, had a total glyphosate application rate of $1.68 \mathrm{~kg}$ ai $/ \mathrm{ha}$. Tall fescue infected with AR542 was no-till drilled (22 kg/ha) into all plots in early October immediately following the final herbicide application. Plots were visually scored for surviving toxic tall fescue 'escape' plants and basal row occupancy counts of tall fescue were collected in the spring following seeding. Plots were harvested throughout the establishment year to determine dry matter yield and an early summer harvest was analysed for total ergot alkaloid concentration. Two years data from the 3 year trial have been analysed thus far. Visual ratings of toxic tall fescue escapes were greater for the single fall glyphosate treatment than for S-S-S. All double application treatments were similar to S-S-S, but visual estimates of escape plants decreased numerically as time between herbicide applications increased. Tall fescue row occupancy in plots where fall herbicides were applied 2, 4 and 6 weeks apart were greater than S-S-S or the single fall herbicide application treatments. Establishment year plot yields were greatest for control and 6 week interval plots and were lowest for the single fall application and S-S-S treatments. Summer ergot alkaloid content was greatest for forage from control plots and lowest for 6 week, S-S-S, 2 week and 4 week treatments respectively. Single fall glyphosate plots had intermediate ergot alkaloid values. These 2 year data indicate that glyphosate applied at 4 or 6 week intervals in the fall can remove toxic tall fescue as effectively as traditional S-S-S methods. On farm tests of the 6 week herbicide application interval ( 6 total locations) in South Carolina and Georgia resulted in less than $1.5 \%$ wild-type infected tall fescue tillers in subsequent AR542 stands. Keywords: novel endophyte, tall fescue toxicosis, pasture renovation 